\title{
Research on the Evolution Path of China's Provincial Innovation Chain Model Based on Complex Network Model
}

\author{
Xiangqian Li $\mathbb{D}^{1,2}$ Caiyun Chen, ${ }^{1}$ Li Huang, ${ }^{3,4}$ Huawei Chen, ${ }^{1}$ and Cunquan Huang ${ }^{1}$ \\ ${ }^{1}$ School of Business, Anhui University of Technology, Maanshan, Anhui 243000, China \\ ${ }^{2}$ School of Business, Nanjing University, Nanjing, Jiangshu 210003, China \\ ${ }^{3}$ School of Management, Hefei University of Technology, Hefei, Anhui 230009, China \\ ${ }^{4}$ School of Management Science and Engineering, Anhui University of Technology, Maanshan, Anhui 243000, China \\ Correspondence should be addressed to Xiangqian Li; linjar2005@ahut.edu.cn
}

Received 28 October 2021; Revised 14 December 2021; Accepted 15 December 2021; Published 29 December 2021

Academic Editor: Tongguang $\mathrm{Ni}$

Copyright ( $\odot 2021$ Xiangqian Li et al. This is an open access article distributed under the Creative Commons Attribution License, which permits unrestricted use, distribution, and reproduction in any medium, provided the original work is properly cited.

\begin{abstract}
By constructing a complex network analysis model, this paper analyzes the data of 31 selected provinces in China from 2010 to 2019, summarizes China's provincial innovation chain development model, and then combined with the time series analyzes the evolution path of the model. The research shows that there is certain group proximity in China's provincial innovation chain in each year, and there are eleven models in ten years. The evolution path of the provincial innovation chain development model is mainly manifested in the development trend of low-level to medium-level and then high-level equilibrium model. Increasing investment and improving efficiency are the leading driving force for the development of China's provincial innovation chain. The medium-level equilibrium model runs through almost all years. Taking this as the node, the innovation driving force gradually changes from high investment to high efficiency.
\end{abstract}

\section{Introduction}

Discussing the mode and evolution of regional innovation chain is helpful to analyze the development direction of regional innovation chain and effectively optimize it and then has important theoretical and practical significance for the choice of the road of regional economic development. At present, the existing research on regional innovation mainly focuses on regional innovation system or regional innovation ecology. For the analysis of regional innovation development and its type differentiation, it has formed a variety of perspectives, such as efficiency perspective [1], system perspective [2], ecological perspective [3], and the perspective of regional innovation capability [4].

In terms of mode division and its development direction, it distinguishes China's high and low innovation capability aggregation areas from the perspective of innovation capability [5]. Several regional innovation models based on the manufacturing industry are compared and analyzed, and it is proposed that the Suzhou model is a better development direction [6]. Some researchers believe that different policies need to be formulated for different models to enhance their independent innovation ability [7]. Based on the analysis of innovation capability, it is found that the development shows the characteristics of agglomeration, especially in the eastern region (Wei Shouhua, 2021). Based on the comparative analysis of China's regional innovation models, it is proposed that the development direction should be the combination of technological innovation and nontechnological innovation [8]. Some believe that regional innovation oriented to regional sustainable development should be established [9]. Based on the analysis of the distinctive regional innovation models of Jiangsu, Zhejiang, and Shanghai, it puts forward two basic construction ways, namely, the primary nature of market orientation and the late nature of government orientation [10].

In terms of research methods, in addition to some qualitative analysis combined with the original index data (such as [6]), quantitative analysis methods mainly focus on cluster analysis, such as $\mathrm{Wu}$ Yilin et al. [11]. Other quantitative methods, such as using factor analysis to measure the coupling degree of regional innovation [12], using Searle 
index and regional Gini index to discuss the spatial distribution and change trend of regional innovation capability [13], and using Moran analysis and spatial econometric model to analyze China's regional innovation capability [14], the application efficiency analysis distinguishes the differences and reasons of regional innovation [4].

In general, the existing studies, based on the distinction of types, do not fully discuss the development direction of its development model from the perspective of innovation chain, especially the development context and evolution path between models. In terms of methods, the existing common methods, such as factor and cluster analysis, can better distinguish various patterns, but they cannot analyze the internal similarity and external discrimination of types better, and their visual display is not explicit enough. The complex network modeling and analysis method can analyze the network relationship between objects by constructing point-to-edge mode and can deeply analyze the internal and external differentiation of patterns on the basis of pattern differentiation.

Therefore, based on the similarity perspective, this paper first comprehensively considers the regional innovation chain from the four dimensions of foundation, input, output, and achievement diffusion and constructs a comprehensive complex network model of 31 provinces and regions in mainland China from 2010 to 2019. Then, through community analysis, it divides subgroups, analyzes the characteristics of community agglomeration, and defines the model type of provincial innovation chain development. Then, combined with the time series, the evolution path of the model is found by analyzing the change of the type proportion of the provincial innovation chain development model in the time series.

\section{Data and Methods}

2.1. Regional Innovation Chain Index System. The relevant indicator systems of regional innovation are representatives, such as the "science, technology, and industry scorecard" of OECD, the national innovation capability index of the United States, and the Innovation Scoreboard of the European Union [15]. In addition, relevant studies have built an urban innovation support and input-output index system based on the theory of innovation vitality [16], emphasizing the importance of non- $R \& D$ indicators [17]. China's typical example is the report on China's regional innovation capability, which constructs an index system in five aspects: innovation environment, knowledge creation, knowledge acquisition, enterprise innovation capability, and economic benefits of innovation [18].

Based on the existing regional innovation evaluation index system, this paper constructs it from the perspective of innovation chain. In terms of index dimension, two dimensions of the main part of the regional innovation chain, innovation input (direct input of resources related to innovation) and innovation output (direct result output of innovation), as well as the postchain result part, innovation result diffusion dimension (transformation effect of innovation direct result), and the front chain foundation part, innovation foundation dimension, are considered. Therefore, the index system covers four links of the regional innovation chain: foundation, input, output, and application of achievements. In the selection of specific indicators, considering the respective contributions or influence of different innovation subjects (government, enterprises, scientific research institutions, and universities) in the innovation chain and drawing on the relevant rules of the EU Innovation Scoreboard, an index system including four dimensions, 12 primary indicators, and 24 specific indicators is constructed. For the selection of primary indicators, the regional innovation foundation includes the human and economic foundation, innovation service foundation, and innovation infrastructure, the regional innovation input includes the input of different innovation subjects (government, enterprises, scientific research institutions, and universities), and the regional innovation output includes the output of different innovation subjects (enterprises, scientific research institutions, and universities). The diffusion of regional innovation achievements includes the diffusion of innovation achievements of above designated enterprises and high-tech enterprises. In addition, this paper mainly considers the similarity between provinces, so the specific index data is mainly relative indicators. See Table 1 for details.

2.2. Data. This paper mainly uses the data from 2010 to 2019 from China Statistical Yearbook, China regional innovation capability report, China Science and technology statistical yearbook, and some local statistical yearbooks to collect and sort out the indicators of 31 provinces in China except Hong Kong, Macao, and Taiwan. Considering the data collection, this paper investigates the provincial innovation with enterprises above designated size instead of enterprises in the innovation subject. Since 2011, the statistical scope of industrial enterprises above designated size has been adjusted from French labor enterprises with an annual main business income of 5 million yuan and above to legal person industrial enterprises with an annual main business income of 20 million yuan and above.

2.3. Model Construction. This paper analyzes the complex network by constructing the complex network model. The complex network mainly analyzes the relationship between objects. This paper takes each province as a network node to form a complex network. By processing the index data, the cosine distance of each included angle is obtained, and the overall complex network diagram of 31 provinces is obtained by using UCINET(v6.5) software. Then, the complex network analysis method is used to analyze the community.

2.3.1. Distance Analysis between Provinces. Specifically, directed weightless network, directed weightless network, directed weightless network, and undirected weightless network belong to complex networks. At the same time, the setting of the relationship between network nodes affects the key core of the network. The interprovincial association complex network constructed in this paper is based on 
TABLE 1: Construction of regional innovation chain index system.

Dimension $\quad$ Primary index

Humanistic economic foundation

Regional innovation foundation

Innovation service foundation

Innovation infrastructure

Government investment

Investment of enterprises above designated size

Regional innovation investment

$R \& D$ organization investment

Investment in colleges and universities

Output of enterprises above designated size

Output of scientific research institutions

Regional innovation output

Output of colleges and universities

Diffusion of innovation achievements of enterprises above designated size

Diffusion of regional innovation achievements
Diffusion of innovation achievements of high-tech enterprises
Specific indicators

Per capita GDP (yuan/person)

Years of education per capita (years/person)

Consumption level of residents (yuan/person)

Per capita technology market transaction amount (by flow direction) (yuan/person)

Number of scientific research institutions per capita (10000 persons)

Average amount of loans from financial institutions for scientific research expenditure of large and medium-sized industrial enterprises (10000 yuan/piece)

Per capita road ownership (km/person)

Average number of mobile phones per 100 households of households in various regions (department/100 households)

Proportion of government $R \& D$ expenditure in local GDP (\%)

Proportion of $R \& D$ personnel of enterprises above designated size

in employees of enterprises above designated size (\%)

Proportion of $R \& D$ expenditure of enterprises above designated size in local GDP (\%)

Proportion of total expenditure of technology purchase, introduction, absorption, and transformation of above designated enterprises in regional GDP (\%)

Proportion of $R \& D$ personnel in $R \& D$ institutions in each region (\%)

Proportion of $R \& D$ expenditure of $R \& D$ institutions in regional GDP (\%)

Proportion of $R \& D$ personnel in colleges and universities in each region (\%)

Proportion of $R \& D$ funds of colleges and universities in regional GDP (\%)

Average number of patent applications of industrial enterprises above designated size in each region (pieces/10000 people) 10000 people have an average of scientific and technological papers published by $R \& D$ institutions in various regions (articles/10000 people)

Average number of patent applications of $R \& D$ institutions in various regions owned by 10000 people (pieces/10000 people) 10000 people have an average of scientific and technological papers published by colleges and universities in various regions (articles/ 10000 people)

Average number of patent applications of colleges and universities in various regions owned by 10000 people (pieces/10000 people)

Proportion of new product output value of enterprises above designated size in total industrial output value (\%) Proportion of output value of new products of high-tech industry in total output value (\%)

Proportion of new product export revenue of high-tech industry in new product sales revenue (\%)

similarity distance and belongs to an undirected weighted network.

To build a complex network model, we must first standardize the index data used. In this process, the final 24 specific indicators are considered because they reflect the corresponding primary indicators and corresponding dimensions. And further, determine the relationship between provinces.

Let the index data of each province be $Y_{i j}=\left\{Y_{i j}, i=1,2 \ldots ; j=1,2 \ldots\right\}, y_{i j}$ represents the score of the $i$ th province in the $j$ th index, $i$ Max 30, and $j \operatorname{Max} 24$. For comparability, the original scores of all provinces under each indicator are divided by the square root of all original scores of the indicator as the standard score. The standard score matrix is

$$
X_{i j}=\frac{Y_{i j}}{\sqrt{1 / I} \sum_{k-1}^{K} Y_{k j}^{2}} .
$$

$$
X_{i j}=\left\{X_{i j}, i=1,2 \ldots ; j=1,2 \ldots\right\} \text {. }
$$

There are many ways to define the distance between provinces, which can reflect many differences between provinces. The included angle cosine distance between provinces $R$ and $S$ can be defined as 


$$
P_{r s}=1-\frac{\sum_{j-1}^{J} X_{r j} X_{z j}}{\sqrt{\sum_{j-1}^{J} X_{r j}^{2}} \sqrt{\sum_{j-1}^{J} X_{s j}^{2}}} .
$$

The distance between $R$ and $\mathrm{S}$ provinces is the cosine of the included angle of the vector composed of 24 indexes. All are nonnegative indicators, so $[0,1]$ is the value range of included angle cosine distance. The similarity of characteristics between provinces or the similarity of the development model can be expressed by this distance. Some provinces are economically developed, but the cosine distance between them and provinces with the same economic level is very large; the reason is that the two provinces have a different bias on a specific index, so the similarity between them is not high. This formula focuses more on similarity and difference in the analysis of provinces.

After setting the relationship between provinces, it is necessary to further set the edges in the complex network, that is, the connection relationship between nodes. Taking each province as the node and the relationship between provinces as the edge, a complex network of provincial innovation chain relationship can be established. For the distance matrix, there are two kinds of methods to establish edges. One is the threshold method; that is, according to the invariant topological properties [19], network connectivity [20], and the minimum spanning tree and event union (Wang $J$, Yang $h, 2009$ ) criteria, set a threshold, and the establishment of edges is set between node pairs whose distance is less than or equal to the threshold. The second type is the maximum edge restriction method; that is, specify a value to establish the maximum upper limit of each node connected to several nearest nodes [21]. This paper adopts the former method, that is, threshold method, and selects the maximum value of the minimum distance between each province and other provinces in the provincial distance matrix as the standard value. If it is less than or equal to this value, it will judge the similarity between the corresponding two provinces as the position and strength of each province in the whole provincial innovation network. Therefore, a complex network model of the provincial innovation chain is constructed.

\subsubsection{Division and Analysis of Complex Network Commu-} nities in Provincial Innovation Chain. According to Newman's research on community structure, in the complex network of the provincial innovation chain, the provinces with a high degree of similarity include angle cosine distance from each community (subgroup). Therefore, the provinces are classified according to the community. On the basis of calculating the cosine distance of the included angle between provinces and determining the value of the distance matrix, the distance matrix is binarized. So the undirected binary relationship network diagram can be formed by the provincial innovation chain network, and then the community analysis of the provincial innovation chain can use the factional division method.
As for the division of communities, there are two methods: cliques and faces. According to the observation results of the complex network graph, it is forcibly divided into several most suitable groups (3-8 groups), so it is divided into various subgroups.

The extended subgroup density relation matrix can be obtained from the analysis of the combined block model [22]. The matrix describes the density relationship between the subgroup itself and the subgroup so that the similarity analysis between and within the subgroup can be carried out. It is also used to detect whether the above grouping is most appropriate.

This paper comprehensively analyzes the community division of provinces from four dimensions in order to find out the similarity of the innovation chain model among provinces. Combined with the time series, the development mode and path of the province are analyzed.

\subsubsection{An empirical Analysis of China's Provincial Innovation} Chain Model and Its Evolution Path. Based on the construction and analysis of the provincial innovation chain complex network model, combined with the data of 24 indicators in 31 provinces from 2010 to 2019, this paper uses UCINET (v6.5) software to analyze the provincial innovation chain complex network.

For the results processed by UCINET (v6.5) software community, we need to further combine the data analysis and then summarize the characteristics of each subgroup to obtain the innovation chain model of different years and provinces in China. Finally, through the comparison of time dimensions, this paper summarizes and refines the evolution path of the provincial innovation chain model.

\subsection{Model Differentiation and Analysis of China's Provincial} Regional Innovation Chain from 2010 to 2019. After the complex network analysis of the data, the complex network diagram is shown in Figure 1 (space limitation, only four annual graphs are shown).

Further, combined with the observation of the complex network diagram of each year, each year is divided into 4-5 subgroups by the mandatory method, and the similarity between subgroups and the appropriateness of grouping are analyzed by expanding the subgroup density relationship matrix. The division of complex network subgroups of provincial innovation chain in each year is shown in Table 2.

Analyze the original data of the relevant indicators of the four modules of each subgroup of the province in each year, and divide the data into five levels: poor, lower middle, middle level, upper middle, and better. Then, combined with the expert analysis method, 11 models are defined for all years. The first appearance and brief analysis of various models are as follows: in 2010, the first subgroup of provinces had poor innovation foundation, low innovation input, low innovation output, and less diffusion of innovation achievements. We defined it as the leading model of low input and low output. The provinces of the second subgroup have weak innovation foundation, medium innovation input, medium innovation output, and diffusion of innovation 


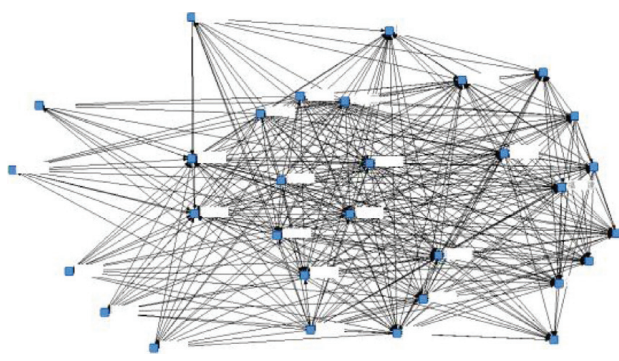

(a)

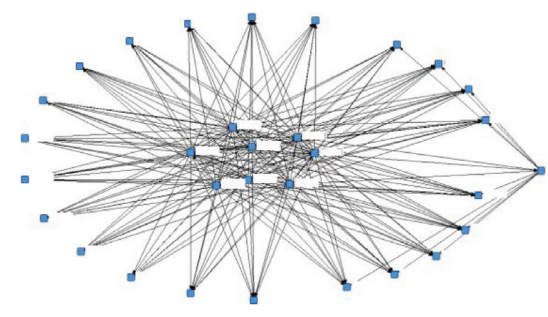

(b)

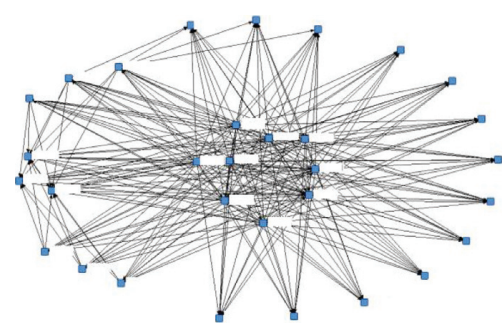

(c)

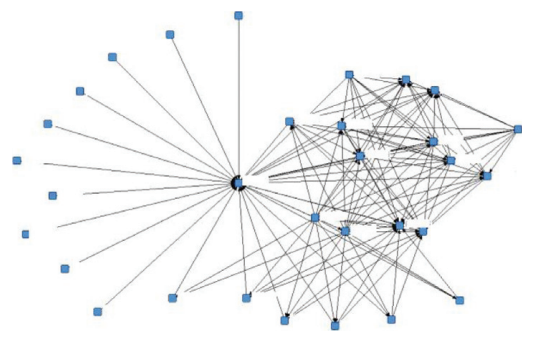

(d)

FIgURE 1: Annual complex network diagram of China's provincial innovation chain: (a) 2010 network diagram; (b) 2013 network diagram; (c) 2016 network diagram; (d) 2019 network diagram.

TABLE 2: Division of complex network subgroups of provincial innovation chain in each year.

\begin{tabular}{|c|c|c|c|}
\hline Year & Subgroup & Province & Pattern \\
\hline \multirow[t]{4}{*}{2010} & $\begin{array}{l}\text { First } \\
\text { subgroup }\end{array}$ & Tibet and Qinghai & $\begin{array}{l}\text { Leading mode of low input and low } \\
\text { output }\end{array}$ \\
\hline & $\begin{array}{l}\text { Second } \\
\text { subgroup }\end{array}$ & Heilongjiang, Guizhou, Inner Mongolia, and Shaanxi & CIC's weak equilibrium model \\
\hline & $\begin{array}{l}\text { Third } \\
\text { subgroup }\end{array}$ & Beijing, Tianjin, Shanghai, Shandong, Fujian, Zhejiang, and Jiangsu & Higher-level equilibrium model \\
\hline & $\begin{array}{l}\text { Fourth } \\
\text { subgroup }\end{array}$ & $\begin{array}{c}\text { Hebei, Shanxi, Jilin, Anhui, Jiangxi, Henan, Liaoning, Hubei, Hunan, } \\
\text { Guangdong, Guangxi, Hainan, Chongqing, Sichuan, Yunnan, Gansu, Ningxia, } \\
\text { and Xinjiang }\end{array}$ & Low-level equilibrium model \\
\hline \multirow[t]{4}{*}{2011} & $\begin{array}{l}\text { First } \\
\text { subgroup }\end{array}$ & Xinjiang, Gansu, and Ningxia & Low-level equilibrium model \\
\hline & $\begin{array}{l}\text { Second } \\
\text { subgroup }\end{array}$ & $\begin{array}{c}\text { Hebei, Yunnan, Heilongjiang, Jiangxi, Sichuan, Guizhou, Tibet, Inner } \\
\text { Mongolia, Jilin, Anhui, and Henan }\end{array}$ & CIC's weak equilibrium model \\
\hline & $\begin{array}{l}\text { Third } \\
\text { subgroup }\end{array}$ & Beijing, Shanghai, Zhejiang, and Guangdong & Higher-level equilibrium model \\
\hline & $\begin{array}{l}\text { Fourth } \\
\text { subgroup }\end{array}$ & $\begin{array}{c}\text { Shanxi, Fujian, Shandong, Hubei, Hunan, Hainan, Shaanxi, Qinghai, Tianjin, } \\
\text { Liaoning, Guangxi, Chongqing, and Jiangsu }\end{array}$ & Medium-level equilibrium model \\
\hline \multirow[t]{4}{*}{2012} & $\begin{array}{c}\text { First } \\
\text { subgroup }\end{array}$ & Sichuan, Yunnan, Tibet, Ningxia, Xinjiang, and Qinghai & High input and high diffusion mode \\
\hline & $\begin{array}{l}\text { Second } \\
\text { subgroup }\end{array}$ & $\begin{array}{c}\text { Shanxi, Inner Mongolia, Heilongjiang, Jiangsu, Shandong, Henan, Guizhou, } \\
\text { Anhui, Hunan, Guangxi, and Chongqing }\end{array}$ & Medium-level equilibrium model \\
\hline & $\begin{array}{l}\text { Third } \\
\text { subgroup }\end{array}$ & Beijing, Tianjin, Shanghai, Zhejiang, Fujian, Guangdong, Jiangxi, and Shaanxi & High-level equilibrium model \\
\hline & $\begin{array}{l}\text { Fourth } \\
\text { subgroup }\end{array}$ & Hebei, Liaoning, Jilin, Hubei, Hainan, and Gansu & CIC's weak equilibrium model \\
\hline \multirow[t]{4}{*}{2013} & $\begin{array}{l}\text { First } \\
\text { subgroup }\end{array}$ & $\begin{array}{c}\text { Hubei, Hainan, Chongqing, Sichuan, Tibet, Shaanxi, Qinghai, Ningxia, and } \\
\text { Xinjiang }\end{array}$ & $\begin{array}{l}\text { Leading mode of high investment } \\
\text { and high diffusion }\end{array}$ \\
\hline & $\begin{array}{l}\text { Second } \\
\text { subgroup }\end{array}$ & Hebei, Liaoning, Anhui, Jiangxi, Henan, Guangdong, and Gansu & Low-level equilibrium model \\
\hline & $\begin{array}{l}\text { Third } \\
\text { subgroup }\end{array}$ & Beijing, Jilin, Heilongjiang, Shanghai, Zhejiang, and Fujian & Higher-level equilibrium model \\
\hline & $\begin{array}{l}\text { Fourth } \\
\text { subgroup }\end{array}$ & $\begin{array}{c}\text { Tianjin, Shanxi, Inner Mongolia, Jiangsu, Shandong, Hunan, Guizhou, } \\
\text { Guangxi, and Yunnan }\end{array}$ & Medium-level equilibrium model \\
\hline 2014 & $\begin{array}{l}\text { First } \\
\text { subgroup }\end{array}$ & $\begin{array}{c}\text { Hebei, Jiangsu, Anhui, Shandong, Guangxi, Sichuan, Yunnan, Tibet, Gansu, } \\
\text { and Xinjiang }\end{array}$ & Medium-level equilibrium model \\
\hline
\end{tabular}


TABLE 2: Continued.

\begin{tabular}{|c|c|c|c|}
\hline Year & Subgroup & Province & Pattern \\
\hline \multirow{7}{*}{2015} & $\begin{array}{l}\text { Second } \\
\text { subgroup }\end{array}$ & Shanxi, Liaoning, Jilin, Hubei, Hainan, Guizhou, Shaanxi, and Qinghai & $\begin{array}{l}\text { Medium base weak equilibrium } \\
\text { model }\end{array}$ \\
\hline & $\begin{array}{l}\text { Third } \\
\text { subgroup }\end{array}$ & $\begin{array}{c}\text { Beijing, Tianjin, Inner Mongolia, Shanghai, Hunan, Guangdong, and } \\
\text { Chongqing }\end{array}$ & High-efficiency output leading mode \\
\hline & $\begin{array}{l}\text { Fourth } \\
\text { subgroup }\end{array}$ & Heilongjiang, Zhejiang, Fujian, Jiangxi, Henan, and Ningxia & Equilibrium model in weak input \\
\hline & $\begin{array}{l}\text { First } \\
\text { subgroup }\end{array}$ & $\begin{array}{c}\text { Shanxi, Liaoning, Shanghai, Henan, Hunan, Guangxi, Xinjiang, Tibet, Gansu, } \\
\text { and Ningxia }\end{array}$ & Medium-level equilibrium model \\
\hline & $\begin{array}{l}\text { Second } \\
\text { subgroup }\end{array}$ & Jilin, Heilongjiang, Zhejiang, Anhui, Guizhou, Shaanxi, and Qinghai & CIC's weak equilibrium model \\
\hline & $\begin{array}{l}\text { Third } \\
\text { subgroup }\end{array}$ & Beijing, Hebei, Jiangsu, Jiangxi, Shandong, Guangdong, and Chongqing & Higher-level equilibrium model \\
\hline & $\begin{array}{l}\text { Fourth } \\
\text { subgroup }\end{array}$ & Tianjin, Inner Mongolia, Fujian, Hubei, Hainan, Sichuan, and Yunnan & $\begin{array}{l}\text { Medium base weak equilibrium } \\
\text { model }\end{array}$ \\
\hline \multirow[t]{4}{*}{2016} & $\begin{array}{l}\text { First } \\
\text { subgroup }\end{array}$ & Hebei, Jiangsu, Shandong, Guangxi, Yunnan, Tibet, and Xinjiang & Equilibrium model in weak input \\
\hline & $\begin{array}{l}\text { Second } \\
\text { subgroup }\end{array}$ & Heilongjiang, Zhejiang, Fujian, Shaanxi, Qinghai, and Ningxia & Medium-level equilibrium model \\
\hline & $\begin{array}{l}\text { Third } \\
\text { subgroup }\end{array}$ & $\begin{array}{c}\text { Beijing, Tianjin, Inner Mongolia, Shanghai, Anhui, Hunan, Guangdong, } \\
\text { Chongqing, and Gansu }\end{array}$ & High-efficiency output leading mode \\
\hline & $\begin{array}{l}\text { Fourth } \\
\text { subgroup }\end{array}$ & Shanxi, Liaoning, Jilin, Jiangxi, Henan, Hubei, Hainan, Sichuan, and Guizhou & $\begin{array}{l}\text { Medium base weak equilibrium } \\
\text { model }\end{array}$ \\
\hline \multirow[t]{5}{*}{2017} & $\begin{array}{l}\text { First } \\
\text { subgroup }\end{array}$ & Heilongjiang, Fujian, Henan, Hubei, Hainan, and Guizhou & Equilibrium model in weak input \\
\hline & $\begin{array}{l}\text { Second } \\
\text { subgroup }\end{array}$ & Zhejiang, Hunan, Chongqing, and Ningxia & $\begin{array}{l}\text { Medium investment and high } \\
\text { diffusion dominated model }\end{array}$ \\
\hline & $\begin{array}{l}\text { Third } \\
\text { subgroup }\end{array}$ & Hebei, Jilin, Anhui, Shandong, Yunnan, and Xinjiang & Medium-level equilibrium model \\
\hline & $\begin{array}{l}\text { Fourth } \\
\text { subgroup }\end{array}$ & $\begin{array}{l}\text { Beijing, Tianjin, Inner Mongolia, Jiangsu, Jiangxi, Guangdong, Guangxi, } \\
\text { Sichuan, Tibet, and Gansu }\end{array}$ & High-efficiency output leading mode \\
\hline & $\begin{array}{l}\text { Fifth } \\
\text { subgroup }\end{array}$ & Shanxi, Liaoning, Shanghai, Shaanxi, and Qinghai & $\begin{array}{l}\text { Leading mode of high foundation } \\
\text { and high yield }\end{array}$ \\
\hline \multirow[t]{5}{*}{2018} & $\begin{array}{l}\text { First } \\
\text { subgroup }\end{array}$ & Tianjin, Inner Mongolia, Jiangxi, Hunan, Sichuan, Tibet, and Gansu & Equilibrium model in weak input \\
\hline & $\begin{array}{l}\text { Second } \\
\text { subgroup }\end{array}$ & $\begin{array}{c}\text { Hebei, Shanxi, Ningxia, Shandong, Guizhou, Yunnan, Shaanxi, Qinghai, and } \\
\text { Xinjiang }\end{array}$ & $\begin{array}{l}\text { Medium base weak equilibrium } \\
\text { model }\end{array}$ \\
\hline & $\begin{array}{l}\text { Third } \\
\text { subgroup }\end{array}$ & Jiangsu, Anhui, Hainan, and Chongqing & $\begin{array}{l}\text { Leading mode of high foundation } \\
\text { and high yield }\end{array}$ \\
\hline & $\begin{array}{l}\text { Fourth } \\
\text { subgroup }\end{array}$ & Heilongjiang, Henan, Hubei, and Guangxi & Medium-level equilibrium model \\
\hline & $\begin{array}{l}\text { Fifth } \\
\text { subgroup }\end{array}$ & Beijing, Liaoning, Jilin, Shanghai, Fujian, Zhejiang, and Guangdong & Higher-level equilibrium model \\
\hline \multirow[t]{4}{*}{2019} & $\begin{array}{l}\text { First } \\
\text { subgroup }\end{array}$ & Beijing, Guangdong, Zhejiang, Jilin, Shanghai, Jiangsu, Fujian, and Shandong & Higher-level equilibrium model \\
\hline & $\begin{array}{l}\text { Second } \\
\text { subgroup }\end{array}$ & $\begin{array}{c}\text { Tianjin, Inner Mongolia, Anhui, Jiangxi, Hebei, Guangxi, Sichuan, Tibet, and } \\
\text { Gansu }\end{array}$ & Equilibrium model in weak input \\
\hline & $\begin{array}{l}\text { Third } \\
\text { subgroup }\end{array}$ & $\begin{array}{c}\text { Shanxi, Liaoning, Hunan, Chongqing, Shaanxi, Qinghai, Guizhou, and } \\
\text { Yunnan }\end{array}$ & Medium-level equilibrium model \\
\hline & $\begin{array}{l}\text { Fourth } \\
\text { subgroup }\end{array}$ & Heilongjiang, Henan, Hubei, Hainan, Ningxia, and Xinjiang & $\begin{array}{l}\text { Medium investment and high } \\
\text { diffusion leading model }\end{array}$ \\
\hline
\end{tabular}

achievements. We define it as the medium input weak equilibrium model. The third subgroup has a good innovation foundation, high innovation input, high innovation output, and good diffusion of innovation achievements. We define it as the high-level equilibrium model. The provincial innovation foundation, innovation input, innovation output, and innovation achievement diffusion of the fourth subgroup are in the lower middle position, which we define as the low-level equilibrium model. In 2011, the provincial innovation base and innovation output of the fourth subgroup were in the lower middle position, and the innovation input and innovation achievement diffusion were in the middle level. We define it as the medium-level equilibrium model. In 2012, the provincial innovation base and innovation output of the first subgroup were in the lower middle position, and the diffusion of innovation input and innovation achievements was good. We defined it as the high input and high diffusion model. In 2014, the provincial 


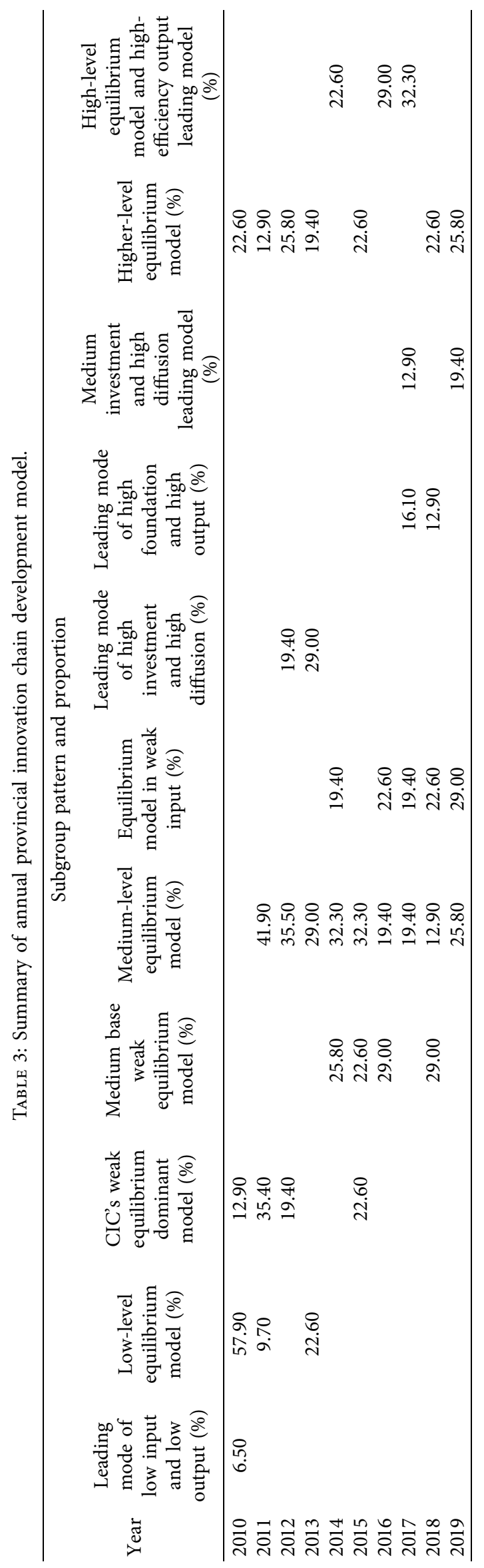


innovation base of the second subgroup was at the middle level, and the innovation input, innovation output, and innovation achievement diffusion were at the lower middle level. We defined it as the medium base weak equilibrium model. The innovation base, innovation output, and innovation achievement diffusion of the third subgroup are in the upper middle position, but the innovation output is very considerable, which we define as the leading mode of highefficiency output. The provinces of the fourth subgroup belong to the innovation foundation, and innovation output and innovation achievements are at the middle level, but the innovation input is at the lower middle position. We define it as the medium equilibrium model of weak input. In 2017, the provincial innovation base and innovation output of the second subgroup were in the lower middle position, the innovation input was in the middle level, and the diffusion of innovation achievements was high, belonging to the dominant mode of medium input and high diffusion. The provinces of the fifth subgroup have a good innovation foundation, the diffusion of innovation input and innovation achievements is at a medium level, and the innovation output is high. We define it as the leading model of high foundation and high output.

\subsection{Analysis of the Evolution Path of China's Provincial In-} novation Chain Development Model. Further, we analyze the evolution path of China's provincial innovation chain development model and compare the number of provinces in each subgroup with the number of provinces in China to calculate the proportion of each model, so the provinces in China can be summarized as shown in Table 3 .

Generally speaking, the main mode of China's provincial innovation chain is around innovation input and innovation output. From 2012, it began to pay attention to the innovation foundation and the diffusion of innovation achievements. In 2014, a high-level balanced development mode began to appear, slowly approaching the high-efficiency development mode. This shows that the development of China's provincial innovation chain is based on innovation input, pays more attention to innovation input and innovation output, and weakens the innovation foundation and the diffusion of innovation achievements. With the development of China's economy, the development of the two dimensions of input and output has affected or spread to other dimensions, showing a fourdimensional synchronous development trend, and began to pay attention to efficiency development and improve the quality of innovation.

At the same time, the annual scores and proportion of the eleven models in all years are quite different, and there are some main models, transition models, and edge models. From the overall trend of the development model of regional innovation chain from 2010 to 2019, the evolution of its main model is from low-level equilibrium model to medium-level equilibrium model and then to high-level equilibrium development. The medium-level equilibrium model runs through almost all years, taking this as the node innovation driving force, and gradually changes from high investment to high efficiency. In this trend, there are corresponding transition modes between the two stages of balanced development mode transformation, which are mainly started and driven by increasing investment or improving efficiency, such as medium input weak equilibrium mode, weak input medium equilibrium mode, and medium input high diffusion dominant mode. Therefore, it can be seen that the leading evolution path of the provincial innovation chain development model is to start with the low-level equilibrium model and develop from the mediumlevel equilibrium to the high-level equilibrium model. The auxiliary evolution path is investment enhancement path and efficiency improvement path.

\section{Research Conclusion}

Using the complex network model and the regional innovation-related data of 31 provinces in mainland China in recent ten years, this paper analyzes the four modules of China's innovation foundation, innovation input, innovation output, and innovation achievement diffusion, so as to investigate the development mode and evolution path of provincial innovation chain in China. The research findings are as follows: (1) Each year, the regional innovation chains of 31 provinces in China show certain group proximity. Each year, all provinces in China can be divided into 4 or 5 modes, and a total of 11 modes are shown in all years: low input and low output leading mode, low-level equilibrium mode, medium input weak equilibrium leading mode, medium foundation weak equilibrium mode, medium-level equilibrium mode, weak input medium equilibrium model, high input high diffusion leading model, high foundation high output leading model, medium input high diffusion leading model, high-level equilibrium model, and high-efficiency output leading model. (2) From 2010 to 2019, China's provincial innovation chain development model developed along the low-level-medium-level-high-level equilibrium model on the main model evolution path. The model evolution was mainly started and driven by increasing investment or improving efficiency. There were corresponding transition models between the two stages of balanced development model transformation, such as medium input weak equilibrium model, weak input medium equilibrium model, and medium input high diffusion dominant model. (3) The development model of China's provincial innovation chain shows a good trend: starting from innovation input, focusing on innovation input and innovation output, and then affecting or spreading to other dimensions, showing a four-dimensional synchronous development trend. However, the medium-level equilibrium model runs through almost all years. Taking this as the node, the innovation driving force gradually changes from high investment to high efficiency.

The enlightenment is as follows: for China as a whole, under the overall trend of the evolution path of China's provincial innovation chain development model, it is necessary to pay attention to the shortcomings of the simple promotion mode of high investment advocated all the time and turn to the high-efficiency promotion of quality and 
high yield and high diffusion of connotation, in order to more reasonably and effectively improve the development level of provincial innovation chain. In addition, for each province, it is necessary to correctly understand the development status of the innovation chain of the province and the previous evolution path and design the promotion ways and paths more in line with its own reality and historical situation.

\section{Data Availability}

The dataset used to support the findings of this study is available from the corresponding author upon request.

\section{Conflicts of Interest}

The authors declare no conflicts of interest.

\section{Acknowledgments}

This work was partially supported by the National Social Science Foundation under Grant no. 18BGL029, the Humanities and Social Sciences Foundation of the https://doi. org/10.13039/100009950Ministry of Education under Grant no. 17YJA630045, and the University Humanities and social science Research Projects at the provincial level under Grant no. SK2018A0069.

\section{References}

[1] Y. Qian, X. Liu, and S. Sun, "Identification of regional differences in China's scientific and technological innovation efficiency and its causes -- Based on major national regional development strategies," Scientific Research, vol. 1-14, 2021.

[2] Q. Zhang, "Research group of Institute of industrial economics, Chinese Academy of social sciences. Key tasks and policy ideas for the construction of China's regional innovation system during the 14th Five Year Plan period," Economic management, vol. 42, no. 08, pp. 5-16, 2020.

[3] D. Wang, F. He, and J. Wu, "Beijing Tianjin Hebei regional innovation ecosystem: operation mechanism and effect evaluation," Scientific and technological progress and countermeasures, vol. 37, no. 10, pp. 53-61, 2020.

[4] X. Yan and B. Yang, "Dual network embedding, institutional environment and regional innovation capability," Scientific research management, vol. 1-18, 2021, http://kns.cnki.net/ $\mathrm{kcms} /$ detail/11.1567.G3.20211011.1444.002.html.

[5] J. Wang, "Jia chenrui. Spatial econometric analysis of China's regional innovation ability and influencing factors," China Science and Technology Forum, vol. 24, no. 12, pp. 73-78, 2009.

[6] Z. Guo and Q. Yang, "Research on regional innovation model and Countermeasures of manufacturing industry -- taking manufacturing industries in Dongguan, Suzhou and Wenzhou as examples," Scientific and technological progress and countermeasures, vol. 27, no. 1, pp. 56-60, 2010.

[7] Li Zhou and Y. Wu, "China's regional innovation capability: factor analysis and cluster research -- Also on the alternative method of factor analysis for the comprehensive evaluation of regional innovation capability," China soft science, vol. 08, pp. 96-103, 2006.

[8] Y. Zhao and Y. Wu, "China's regional innovation model and new development direction--an analysis based on the innovation index of 31 provinces, autonomous regions and cities in China from 2001 to 2009," Economic theory and economic management, vol. 2010, no. 12, pp. 69-76, 2010.

[9] c Peng, "Regional innovation chain for sustainable development: concept, function and characteristics," China Science and Technology Forum, vol. 17, no. 3, pp. 76-80, 2002.

[10] D. Chen, "Research on regional innovation chain model and its construction in the Yangtze River Delta," Scientific development, vol. 02, pp. 19-28, 2010.

[11] Y. Wu, "Research on the path of coordinated development of China's regional innovation chain--An Empirical Analysis Based on regional integrated innovation index," Research world, vol. 01, pp. 53-57, 2013.

[12] Yi Su, X. An, Y. Sun, and Y. Guo, "Measurement model construction and empirical research on coupling degree of regional innovation chain," Journal of Systems Engineering, vol. 33, no. 03, pp. 398-411, 2018.

[13] W. Shouhua, J. Chen, and yuan he, "Spatial distribution and change trend of regional innovation capability," Scientific research management, vol. 32, no. 4, pp. 152-160, 2011.

[14] J. Wang and H. Yang, "Complex network-based analysis of air temperature data in China," Modern Physics Letters B, vol. 23, no. 14, pp. 1781-1789, 2009.

[15] H. Li, X. Zhou, and Li Hong, "Review of regional innovation chain evaluation," Science and technology management research, no. 1, pp. 13-18, 2010.

[16] K. Xie, S. Zhang, and H. Liu, Comparative Analysis of Innovation Ability of Key Cities, Management world, no. 01, , pp. 176-177, Netherland, 2009.

[17] H. Zhu, "Research on index system of regional innovation capability evaluation," Scientific research management, vol. 25, no. 3, pp. 30-35, 2004.

[18] X. Liu, T. Gao, and editor in chief, China's Regional Innovation Capability Report 2012, Science Press, Beijing, 2013.

[19] Y. Yang and H. Yang, "Complex network-based time series analysis," Physica A: Statistical Mechanics and Its Applications, vol. 387, no. 5-6, pp. 1381-1386, 2008.

[20] L. Sun, M. Li, and L. Jiang, "Comparative analysis of the gene co-regulatory network of normal and cancerous lung," Physica A, vol. 384, pp. 739-746, 2007.

[21] X. Xu, J. Zhang, and M. Small, "Superfamily phenomena and motifs of networks induced from time series," Proceedings of the National Academy of Sciences of the United States of America, vol. 105, pp. 19601-19605, 2008.

[22] S. Wasserman and K. Faust, Social Network Analysis: Methods and Applications, pp. 397-401, Cambridge University Press, Cambridge,USA, 1994. 